\title{
Article \\ Clinical Factors Associated with Reinfection versus Relapse in Infective Endocarditis: Prospective Cohort Study
}

\author{
Jorge Calderón-Parra $1,+\left(\mathbb{D}\right.$, Martha Kestler $2,+\mathbb{C}$, Antonio Ramos-Martínez $1, * \mathbb{C}$, Emilio Bouza ${ }^{2,3}$, \\ Maricela Valerio ${ }^{2}{ }^{-0}$, Arístides de Alarcón ${ }^{4}$, Rafael Luque ${ }^{4}$, Miguel Ángel Goenaga ${ }^{5}$, Tomás Echeverría ${ }^{6}$, \\ $M^{\text {a }}$ Carmen Fariñas ${ }^{7}$, Juan M. Pericàs ${ }^{8}$, Guillermo Ojeda-Burgos ${ }^{9}$, Ana Fernández-Cruz ${ }^{1}{ }^{\mathbb{D}}$, Antonio Plata ${ }^{10}$, \\ David Vinuesa ${ }^{11}$, Patricia Muñoz ${ }^{2,3}$ and on behalf of the GAMES Investigators $\ddagger$
}

check for

updates

Citation: Calderón-Parra, J.; Kestler, M.; Ramos-Martínez, A.; Bouza, E.;

Valerio, M.; de Alarcón, A.; Luque, R.; Goenaga, M.Á.; Echeverría, T.;

Fariñas, M.C.; et al. Clinical Factors Associated with Reinfection versus Relapse in Infective Endocarditis: Prospective Cohort Study. J. Clin. Med. 2021, 10, 748. https://doi.org/ $10.3390 /$ jcm 10040748

Academic Editor: Vincenzo Calderone

Received: 17 January 2021

Accepted: 8 February 2021

Published: 13 February 2021

Publisher's Note: MDPI stays neutral with regard to jurisdictional claims in published maps and institutional affiliations.

Copyright: (c) 2021 by the authors. Licensee MDPI, Basel, Switzerland. This article is an open access article distributed under the terms and conditions of the Creative Commons Attribution (CC BY) license (https:// creativecommons.org/licenses/by/ $4.0 /)$.
1 Unidad de Enfermedades Infecciosas, Hospital Universitario Puerta de Hierro- Majadahonda (IDIPHSA), 28222 Madrid, Spain; jorge050390@gmail.com (J.C.-P.); anafcruz999@gmail.com (A.F.-C.)

2 Servicio de Microbiología Clínica y Enfermedades Infecciosas, Hospital General Universitario Gregorio Marañón, 28007 Madrid, Spain; kestler.martha@gmail.com (M.K.); emilio.bouza@gmail.com (E.B.); mavami_valerio@yahoo.com.mx (M.V.); pmuñoz@micro.hggm.es (P.M.)

3 Enfermedades Respiratorias-CIBERES (CB06/06/0058), Facultad de Medicina, Universidad Complutense de Madrid, 28040 Madrid, Spain

4 Clinical Unit of Infectious Diseases, Microbiology and Preventive Medicine Infectious Diseases Research Group, University of Seville/CSIC/University Virgen del Rocío and Virgen Macarena (IBIS), 41013 Sevilla, Spain; aa2406ge@yahoo.es (A.d.A.); rafaeluquemarquez@gmail.com (R.L.)

5 Servicio de Enfermedades Infecciosas, Hospital Universitario Donostia, 20010 San Sebastián, Spain; goenagasanchez@gmail.com

6 Servicio de Cardiología, Hospital Donosti, 20010 San Sebastián, Spain; tomas.echeverriagarcia@osakidetza.eus

7 Infectious Diseases Unit, Hospital Universitario Marqués de Valdecilla, University of Cantabria, 39008 Santander, Spain; mcfarinas@humv.es

8 Infectious Disease Department, Hospital Clínic de Barcelona (IDIBAPS), 08036 Barcelona, Spain; pericasjm@gmail.com

9 Unidad de Gestión Clínica de Enfermedades Infecciosas, Hospital Universitario Virgen de la Victoria, 29010 Málaga, Spain; guilleojeda@gmail.com

10 Servicio de Enfermedades Infecciosas, Hospital Regional de Málaga, 29010 Málaga, Spain; antonio-plata@hotmail.com

11 Servicio de Medicina Interna y Enfermedades Infecciosas, Hospital Clínico San Cecilio, 18016 Granada, Spain; vinudav@yahoo.es

* Correspondence: aramos220@gmail.com; Tel.: +34-638-211-120; Fax: +34-91191-6807

+ Equivalent merits.

$\ddagger$ GAMES Investigators are listed in Acknowledgments.

\begin{abstract}
We aimed to identify clinical factors associated with recurrent infective endocarditis (IE) episodes. The clinical characteristics of 2816 consecutive patients with definite IE (January 2008-2018) were compared according to the development of a second episode of IE. A total of 2152 out of 2282 (94.3\%) patients, who were discharged alive and followed-up for at least the first year, presented a single episode of IE, whereas 130 patients $(5.7 \%)$ presented a recurrence; 70 cases $(53.8 \%)$ were due to other microorganisms (reinfection), and 60 cases $(46.2 \%)$ were due to the same microorganism causing the first episode. Thirty-eight patients $(29.2 \%)$, whose recurrence was due to the same microorganism, were diagnosed during the first 6 months of follow-up and were considered relapses. Relapses were associated with nosocomial endocarditis (OR: 2.67 (95\% CI: 1.37-5.29)), enterococci (OR: 3.01 (95\% CI: 1.51-6.01)), persistent bacteremia (OR: 2.37 (95\% CI: 1.05-5.36)), and surgical treatment (OR: $0.23(0.1-0.53)$ ). On the other hand, episodes of reinfection were more common in patients with chronic liver disease (OR: 3.1 (95\% CI: 1.65-5.83)) and prosthetic endocarditis (OR: 1.71 (95\% CI: 1.04-2.82)). The clinical factors associated with reinfection and relapse in patients with IE appear to be different. A better understanding of these factors would allow the development of more effective therapeutic strategies.
\end{abstract}

Keywords: endocarditis; bacterial; recurrence; Enterococcus; bacteremia; cardiac surgical procedures; liver disease 


\section{Introduction}

Recurrent infective endocarditis (IE) is a feared complication that is associated with increased mortality $[1,2]$. Despite current therapies and prophylactic measures to prevent further episodes of IE, about $5-10 \%$ of patients eventually develop this condition [1,3-5].

Recurrent episodes of IE are classified as relapse or reinfection depending on the etiology and pathogenesis. The lack of eradication of the infection in the valve or adjacent tissue may be the cause of relapse of IE [6]. Conversely, reinfection is associated with new episodes of bacteremia in patients, where a condition predisposing to the development of IE may also be present [7]. Episodes of IE recurrences caused by a different microorganism than the previous one are usually considered as reinfections. On the other hand, when the new episode is caused by the same species, there is an inclination to consider it a relapse. According to molecular biology studies, the probability of the same strain causing a relapse is greater if recurrent IE occurs during the first six months after the initial episode [8]. Beyond that period there is uncertainty about its pathogenesis.

To date, most studies investigating recurrent episodes of endocarditis have not differentiated between relapse and reinfection, thereby preventing the identification of risk factors associated with each of them $[1-3,5,9,10]$. A recent study that specifically analyzed the risk factors of these two types of infections included a high number of intravenous drug users (IDUs), a rare practice in Spain in recent years [4]. Our aim was to identify the clinical factors associated with the development of relapse or reinfection in a large prospective and recent nationwide cohort of IE.

\section{Methods}

\subsection{Design and Setting}

A prospective cohort study, including cases of definite IE according to modified Duke criteria, was performed from January 2008 to June 2018 in the Games Cohort (Supportive Group for the Management of Infective Endocarditis in Spain). This registry was formed and maintained by 27, mainly tertiary, Spanish hospitals. Multidisciplinary "Endocarditis teams" in each participating institution completed standardized case report forms for subjects presenting IE episodes and follow-up data that included clinical, microbiological, and echocardiographic sections [11]. The database was continuously reviewed by a coordinator and a data manager who were responsible for contacting the different hospitals to keep the information accurately updated. Regional and local ethics committees approved the study, and all patients gave their informed consent.

\subsection{Definitions}

IE was defined using the modified Duke criteria [12]. Microbiological diagnosis was determined by blood or valve culture [11]. Transthoracic (TTE) and transesophageal (TEE) echocardiography were performed on patients with clinical or microbiological suspicion of IE according to European guidelines, or to diagnose valve dysfunction and intracardiac complications, such as abscesses, vegetation, pseudoaneurysms, or fistulae [13]. To consider hospital-acquired, non-healthcare-related, and community-acquired IE, definitions from previous studies were followed [10]. All necessary variables were collected to calculate the Charlson Comorbidity Index [14]. Recurrent episodes of IE were classified as relapses or reinfections. Relapses were defined as episodes of recurrent IE caused by the same organism detected within the first six months after completing the initial treatment and reinfections as new episodes of IE caused by a different microorganism within the followup period [13,15]. Although it is generally considered that repeated episodes of IE caused by the same species, but that appear after the first six months of follow-up, represent reinfections, a study based on molecular biology showed that some of these cases may correspond to relapses $[8,13]$. Due to this lack of certainty, it was decided not to include in either of the two groups the cases caused by the same species after the first six months of follow-up. No molecular biology studies were performed to corroborate that the cases considered as relapses were caused by the same strain. Only the first episode of recurrent 
endocarditis was analyzed. Exclusion criteria were possible IE according to modified Duke criteria, death during first IE episode admission, and less than 12 months' follow-up after discharge.

The Cockcroft-Gault equation was used to calculate creatinine clearance [16]. Preepisode renal insufficiency was defined as plasma creatinine over $1.4 \mathrm{mg} / \mathrm{dL}$. New or worsening renal insufficiency during an IE episode was defined as a decrease in baseline creatinine clearance, or a minimum $25 \%$ increase in plasma creatinine, or creatinine levels over $1.4 \mathrm{mg} / \mathrm{dL}$, when a previous analysis had been normal. Persistent bacteremia was defined as positive blood cultures more than seven days after effective antibiotic therapy.

\subsection{Statistical Analysis}

Quantitative variables were reported as median and interquartile ranges (IQRs) and qualitative variables as figures and percentages. In the comparisons with the different types of patients, only the variables corresponding to the first episode were analyzed. Continuous variables were compared with Student's $t$-test, and categorical variables were compared using the chi-square test or Fisher's exact test when appropriate. Stepwise logistic regression analyses were performed including variables present at admission with a $p$ value $<0.1$ in the univariate analysis, but also taking into account the clinical significance of each variable and the number of patients that reported the studied event. A two-sided $p<0.05$ was considered to be statistically significant. Statistical analyses were performed using SPSS version 18 software (SPSS Inc., Chicago, IL, USA).

\section{Results}

During the study period, 2816 consecutive patients with definite IE were identified. During admission, 265 (9.4\%) died, and 269 (9.6\%) were lost or did not complete 12 months of follow-up. Out of the remaining 2282 subjects, 2152 (94.3\%) had a single IE episode and $130(5.7 \%)$ a second episode (Figure 1). The mean follow-up of IE patients was 3.4 years (range, $1-6.25$ years).

The annual risk of suffering from a recurrent episode of IE in our study was $0.62 \%$ per patient-year. In the group that suffered a second episode, the causative microorganism was the same as in the initial episode in $60(2.6 \%)$, and a different microorganism in $70(3.1 \%)$. The clinical characteristics of the initial episode of IE, depending on whether the recurrence was caused by the same or different species, are shown in the Supplementary material (Table S1). Of the 60 patients who had a new episode of IE caused by the same species, $38(1.7 \%)$ were diagnosed during the first six months of follow-up (and were considered to definitely suffer a relapse) and 22 after the first six months of follow-up $(0.9 \%)$. The proportion of recurrent IE episodes caused by the same species during the first six months after completing treatment was $63.3 \%$ (38 out of 60 cases, $p=0.005$ ), $36.4 \%$ between the 7 th and 12th months ( 8 out of 22 cases, $p=0.437$ ), and $29.1 \%$ when the episode appeared after the first year (14 out of $48(29.1 \%), p=0.005$, Figure 2). Fifty-six patients $(53.1 \%)$ underwent surgery after being diagnosed with recurrent IE. Subjects with liver cirrhosis, parenteral drug users, cases of prosthetic endocarditis, and patients who did not undergo surgical treatment had an increased risk of a second IE episode (Table 1). When the same variables were used for multivariate analyses, only liver cirrhosis and prosthetic endocarditis were associated with recurrent episodes (Table 1).

The characteristics of patients who suffered relapses (due to the same microorganism during the first six months after treatment) during the initial IE episode were compared with those who had a single episode of IE (Table 2). Individuals who presented with a relapse of the initial IE showed differences in a series of variables, such as nosocomial acquisition of the infection, IE due to Enterococcus spp., persistent bacteremia, and not receiving surgical treatment. Among the 14 patients who had a relapse of IE and who had surgical indications, 7 patients $(50 \%)$ did not undergo surgery. Reasons for not carrying out cardiac surgery when indicated included liver cirrhosis (three cases), technical complexity (two cases), and hemodynamic instability and patient rejection (one case each). None of 
the patients whose relapse was due to enterococci underwent surgery, compared to $49 \%$ of those who had only one episode $(p<0.001)$. The following variables were included in the multivariable analysis, which showed that all were independently associated with the relapses: hospital-acquired IE, enterococcal IE persistent bacteremia, and not performing treatment when indicated (Table 2).

Patients with definite native valve infectious endocarditis $n=2816$

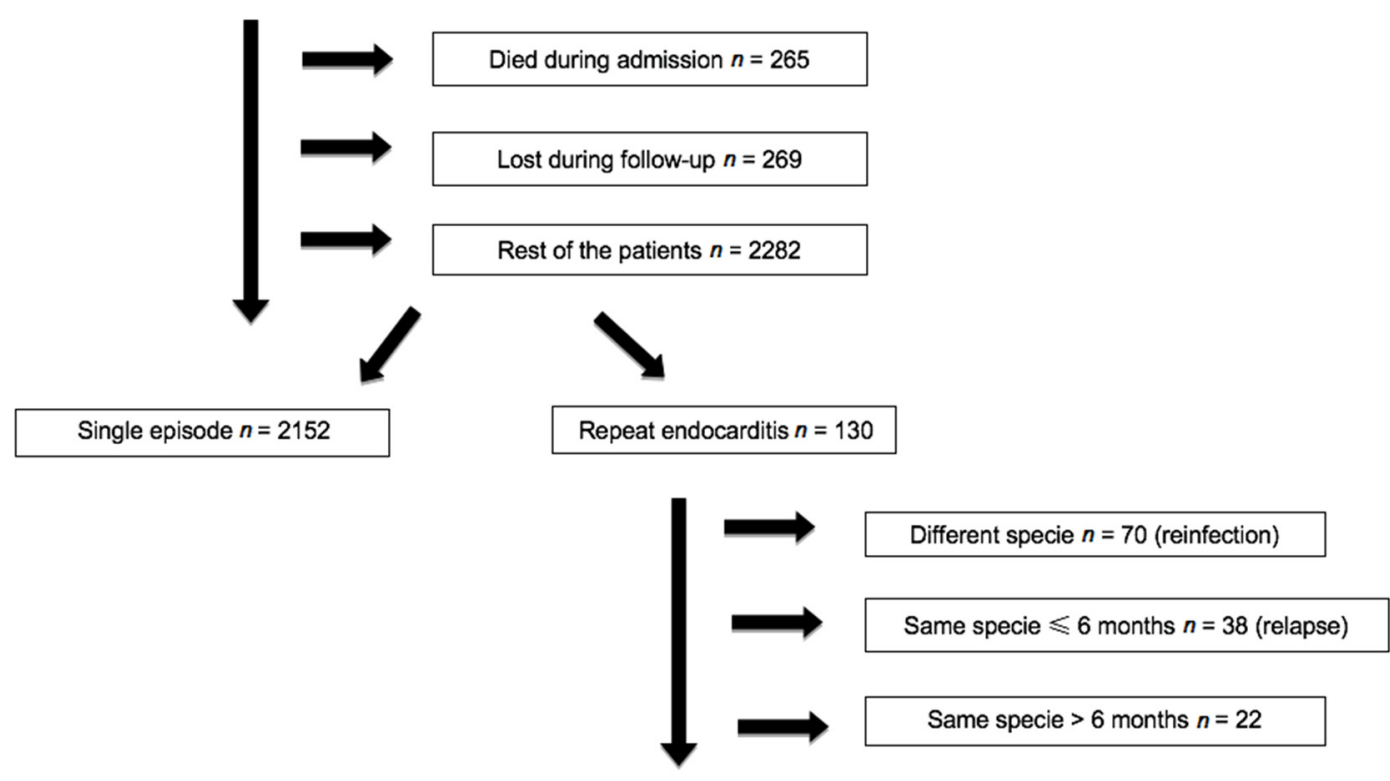

Figure 1. Flowchart showing patients presenting with definite valve infective endocarditis according to suffering from a repeat episode (Games cohort).

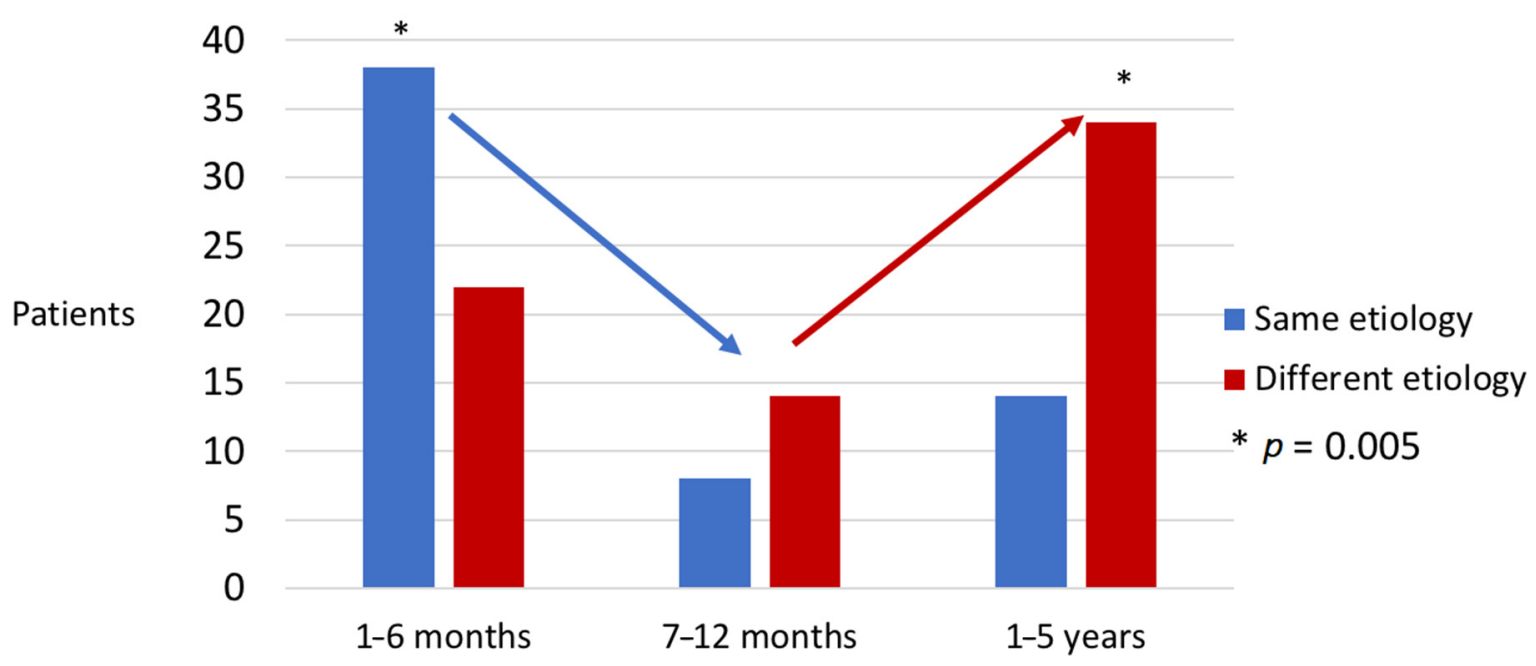

Figure 2. Distribution of cases according to etiology of recurrent IE and the time elapsed since the first episode. ${ }^{*} p=0.005$.

Compared to patients with a single IE episode, patients suffering reinfection had significantly higher rates of liver cirrhosis, prosthetic IE, and IE caused by anaerobic bacteria, whereas they presented significantly lower rates of IE caused by S. aureus (Table 2). The variables included in the multivariable analysis were liver cirrhosis, prosthetic endocarditis, and IE caused by anaerobic bacteria. Finally, all of them were significant variables (Table 2). 
Table 1. Characteristics of the initial episode in patients who developed recurrent infective endocarditis in comparison with patients who presented one episode.

\begin{tabular}{|c|c|c|c|c|}
\hline & $\begin{array}{l}\text { Recurrent Endocarditis } \\
\qquad(n=130)\end{array}$ & $\begin{array}{l}\text { One Episode } \\
\quad(n=2152)\end{array}$ & OR $(95 \% \text { CI })^{1}$ & $p$ \\
\hline Age (years) & $65(46-74)$ & $66(53-75)$ & & 0.222 \\
\hline Male gender & $88(67.7)$ & $1505(69.9)$ & & 0.658 \\
\hline Hospital-acquired & $41(31.5)$ & $516(23.9)$ & & 0.065 \\
\hline Non-nosocomial healthcare related & $14(10.7)$ & $175(8.1)$ & & 0.370 \\
\hline Community-acquired & $75(57.7)$ & $1461(67.9)$ & & 0.021 \\
\hline Diabetes mellitus & $32(24.6)$ & $538(25.0)$ & & 0.995 \\
\hline Coronary disease & $37(28.5)$ & $541(25.2)$ & & 0.458 \\
\hline Peripheral arterial disease & $9(6.9)$ & $196(9.1)$ & & 0.491 \\
\hline Cerebrovascular disease & $22(16.9)$ & $240(11.1)$ & & 0.062 \\
\hline Previous renal failure & $23(17.7)$ & $410(19.1)$ & & 0.701 \\
\hline Chronic hemodialysis & $5(3.8)$ & $79(3.6)$ & & 0.891 \\
\hline Chronic liver disease & $21(16.3)$ & $155(7.2)$ & $2.34(1.39-3.9)$ & $<0.01$ \\
\hline Injection drug user & $8(6.2)$ & $47(2.2)$ & $2.06(0.87-4.93)$ & 0.004 \\
\hline Neoplasia & $22(16.9)$ & $281(13.0)$ & & 0.259 \\
\hline Age-adjusted Charlson Comorbidity Index (points) & $4(2-6)$ & $4(2-6)$ & & 0.819 \\
\hline \multicolumn{5}{|l|}{ Site of infection } \\
\hline Native valve & $67(51.5)$ & $1317(61.2)$ & & 0.029 \\
\hline Prosthetic valve & $47(36.2)$ & $580(27.0)$ & $1.64(1.12-2.39)$ & 0.022 \\
\hline Cardiac device & $15(11.5)$ & $277(12.9)$ & & 0.659 \\
\hline \multicolumn{5}{|l|}{ Involved valve } \\
\hline Mitral & $69(53.1)$ & $1041(48.4)$ & & 0.297 \\
\hline Aortic & $52(40.0)$ & $862(40.1)$ & & 0.990 \\
\hline Tricuspid & $6(4.6)$ & $131(6.1)$ & & 0.493 \\
\hline Pulmonary & $3(2.3)$ & $26(1.2)$ & & 0.277 \\
\hline \multicolumn{5}{|l|}{ Microbiology } \\
\hline \multicolumn{5}{|l|}{ Gram-positive bacteria } \\
\hline Coagulase-negative staphylococci & $22(16.9)$ & $332(15.4)$ & & 0.647 \\
\hline S. aureus & $22(16.9)$ & $415(19.3)$ & & 0.506 \\
\hline Enterococcus spp. & $25(19.2)$ & $302(14.0)$ & & 0.101 \\
\hline Streptococcus spp. & $30(23.1)$ & $654(30.4)$ & & 0.077 \\
\hline Gram-negative bacilli & $9(6.9)$ & $89(4.1)$ & & 0.128 \\
\hline Anaerobic bacteria & $4(3.1)$ & $28(1.3)$ & & 0.094 \\
\hline Candida & $1(0.8)$ & $23(1.1)$ & & 0.745 \\
\hline Polymicrobial & $1(0.8)$ & $38(1.8)$ & & 0.395 \\
\hline Other microorganisms & $18(13.8)$ & $224(10.4)$ & & 0.216 \\
\hline Negative cultures & $11(8.5)$ & $186(8.6)$ & & 0.943 \\
\hline Septic shock & $5(3.8)$ & $129(5.9)$ & & 0.412 \\
\hline Persistent bacteremia & $15(11.5)$ & $206(9.5)$ & & 0.559 \\
\hline CNS vascular events & $19(14.6)$ & $318(14.7)$ & & 0.938 \\
\hline Embolism & $28(21.5)$ & $435(20.2)$ & & 0.800 \\
\hline Heart failure & $43(33.0)$ & $651(30.2)$ & & 0.560 \\
\hline New or worsening renal insufficiency & $39(30.0)$ & $588(27.3)$ & & 0.573 \\
\hline \multicolumn{5}{|l|}{ Echocardiographic findings } \\
\hline Vegetation & $86(66.2)$ & $1532(71.2)$ & & 0.216 \\
\hline Perivalvular abscess & $17(13.2)$ & $272(12.7)$ & & 0.970 \\
\hline Valve perforation or rupture & $14(10.7)$ & $281(13.2)$ & & 0.448 \\
\hline Pseudoaneurysm & $4(3.1)$ & $101(4.7)$ & & 0.692 \\
\hline Intracardiac fistula & $3(2.3)$ & $43(2.0)$ & & 0.966 \\
\hline Surgical indication & $75(57.6)$ & $1319(61.2)$ & & 0.468 \\
\hline Surgery performed & $56(43.1)$ & $1119(52.0)$ & $0.74(0.52-1.1)$ & 0.048 \\
\hline Surgery indicated but not performed & $19(14.6)$ & $200(9.3)$ & & 0.232 \\
\hline Device extraction & $9(60)$ & $233(84.1)$ & & 0.016 \\
\hline Duration of antibiotic treatment & $42(32-50)$ & $42(30-47)$ & & 0.323 \\
\hline Hospital stay (days) & $40(27-53)$ & $40(25-54)$ & & 0.766 \\
\hline
\end{tabular}

CNS: central nervous system. Quantitative variables are reported with median and interquartile range. ${ }^{1}$ Multivariate analysis. 
Table 2. Characteristics of the initial episode in patients who developed recurrences in comparison with patients who presented one episode.

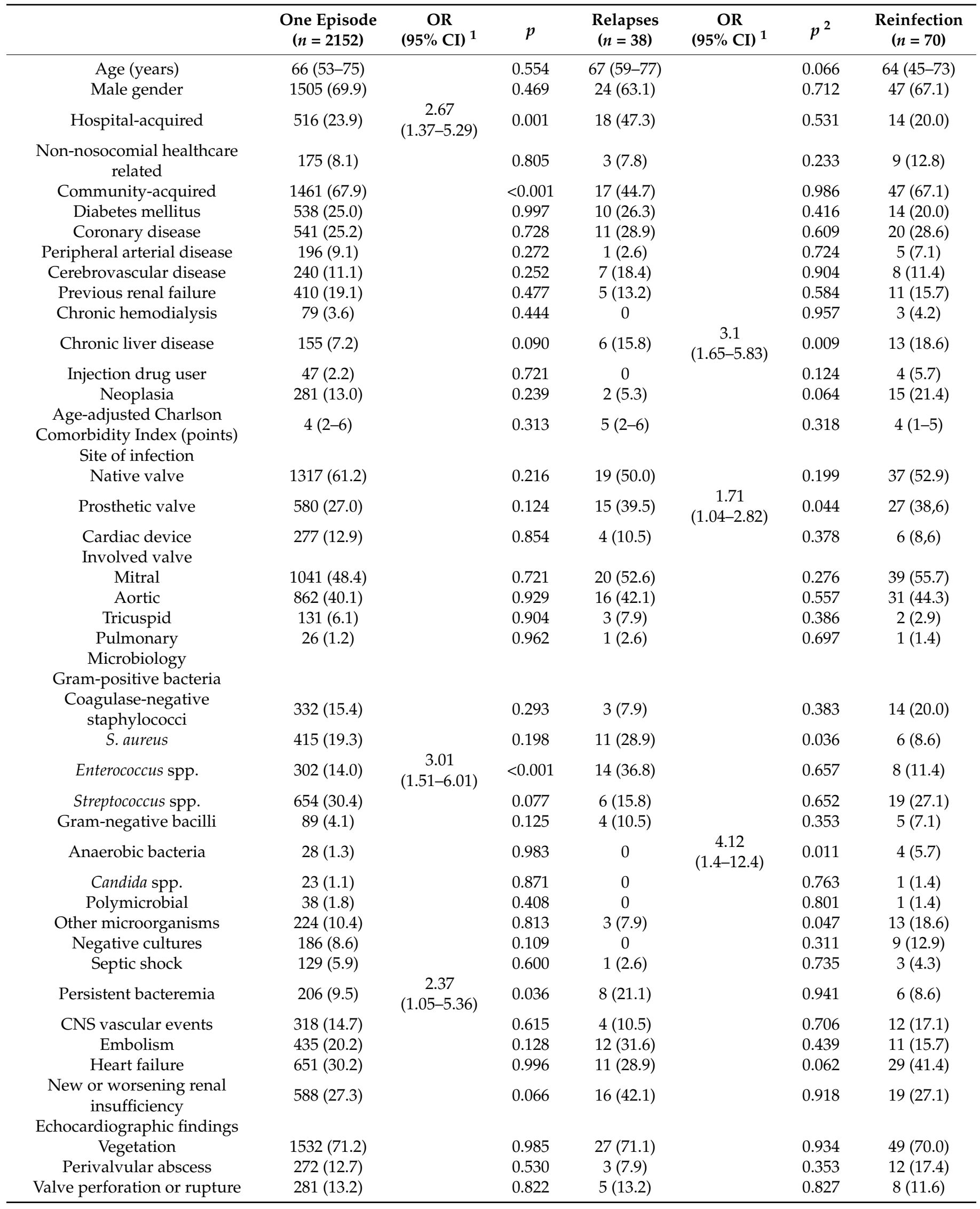


Table 2. Cont.

\begin{tabular}{|c|c|c|c|c|c|c|c|}
\hline & $\begin{array}{l}\text { One Episode } \\
\quad(n=2152)\end{array}$ & $\begin{array}{c}\text { OR } \\
(95 \% \text { CI })^{1}\end{array}$ & $p$ & $\begin{array}{l}\text { Relapses } \\
(n=38)\end{array}$ & $\begin{array}{c}\text { OR } \\
(95 \% \text { CI })^{1}\end{array}$ & $p^{2}$ & $\begin{array}{l}\text { Reinfection } \\
\quad(n=70)\end{array}$ \\
\hline Pseudoaneurysm & $101(4.7)$ & \multirow{7}{*}{$\begin{array}{c}0.23 \\
(0.1-0.53)\end{array}$} & 0.834 & $1(2.6)$ & \multirow{7}{*}{$\begin{array}{c}1.03 \\
(0.49-2.21)\end{array}$} & 0.897 & $3(4.3)$ \\
\hline Intracardiac fistula & $43(2.0)$ & & 0.771 & 0 & & 0.370 & $3(4.3)$ \\
\hline Surgical indication & $1319(61.2)$ & & 0.003 & $14(36.8)$ & & 0.111 & $50(71.4)$ \\
\hline Surgery performed & $1119(52.0)$ & & 0.001 & $7(18.4)$ & & 0.231 & $42(60.0)$ \\
\hline Surgery indicated not performed & $200(9.3)$ & & 0.211 & 7 (18.4) & & 0.971 & 8 (11.4) \\
\hline Duration of antibiotic treatment & $40(25-54)$ & & 0.662 & $40(27-56)$ & & 0.655 & $42(28-53)$ \\
\hline Hospital stay (days) & $42(30-47)$ & & 0.882 & $42(30-49)$ & & 0.092 & $42(37-49)$ \\
\hline
\end{tabular}

CNS: central nervous system. PVIE: prosthetic valve infectious endocarditis. Quantitative variables are reported with median and interquartile range. ${ }^{1}$ Multivariate analysis. ${ }^{2}$ Comparison of reinfection cases compared to cases that presented a single episode of infective endocarditis.

The relationship between the microbiology of the first and second episodes is shown in a Supplementary material (Table S2).

\section{Discussion}

This study represents the largest cohort of patients with IE and examines the clinical profile of recurrent endocarditis. The large number of subjects in our national cohort allowed us to identify clinical factors associated with recurrent IE in general, and for relapses and reinfections separately.

\subsection{Clinical Factors Associated with Recurrence (Reinfection or Relapse)}

We found a recurrence rate of $6 \%$. This figure is similar to those of other series, with recurrent endocarditis ranging between $4 \%$ and $16 \%[2,3,5,10,17]$. The proportion of relapses was lower than reinfections $(1.7 \%$ vs. $3.1 \%)$, as observed in most analyses, particularly in those with longer follow-up periods [1-3,5,17]. Chronic liver disease and prosthetic endocarditis were associated with recurrent IE. Notably, we did not find that age was associated with recurrences, as prior studies did [5,18].

\subsection{Clinical Factors Associated with Relapse}

Relapse episodes suggest that treatment of the initial episode has been unsuccessful because of insufficient antimicrobial or surgical treatment that may allow a focus of infection (cardiac or metastatic) to remain. In our cohort, healthcare-associated IE, enterococcal etiology, persistent bacteremia, and not receiving cardiac surgery were risk factors for relapse. Alagna et al. also found that healthcare acquisition was associated with relapses [3]. It is likely that healthcare acquisition, enterococcal etiology, and low rates of cardiac surgery are tightly intertwined factors occurring mostly in elderly and fragile patients with high surgical risk [13]. Moreover, the significantly higher rates of relapse in enterococcal IE are an increasingly known phenomenon [19]. The observation that none of the patients who presented a relapsing enterococcal IE had undergone surgery reinforces the relevant role of surgical intervention in preventing relapses of enterococcal IE [20]. Further research is needed to elucidate the role of the type and length of antibiotic treatment in the frequency of relapses in enterococcal IE [19,21]. On the other hand, the relationship between persistent bacteremia and relapses is not surprising. The delay in microbiological eradication may be related to the initial high level of bacterial inoculum in the bloodstream, an uncontrolled focus of infection, the use of an antibiotic regimen that is not fully effective (due to inadequate penetration of the drug into vegetation or difficultto-treat microorganisms), or the development of resistance during treatment. All these circumstances could delay the definitive cure of the infection and favor the development of a relapse [1]. 


\subsection{Clinical Factors Associated with Reinfection}

Reinfection is related to the occurrence of repetitive episodes of bacteremia in patients who may have heart or vascular conditions that predispose them to implantation and growth of bacteria. Reinfection was significantly associated with prosthetic IE, chronic liver disease, and IE due to anaerobic bacteria. The increased risk of recurring IE in patients with prosthetic valves had already been established in prior studies $[2,9,12]$, and it is likely linked to the ability of bacteria to adhere to artificial surfaces, such as the sewing ring, and the tissue damage caused by prior IE episodes [3,9].

It has been shown that patients suffering from liver cirrhosis are at higher risk of developing IE than the general population. Similarly, the percentage of patients intervened is low and mortality high (particularly Child stage $C$ subjects) [22]. The increased risk of reinfection in these patients may be related to increased gut permeability, predisposition to bacteremia, immune dysfunction, and a frequent need for invasive procedures [23]. Conducting randomized studies to clarify the usefulness of antibiotic prophylaxis in endoscopic procedures, such as esophageal variceal ligation, seems to be an interesting goal, but it has to cope with the reduced number of cases of infectious endocarditis in cirrhotic patients [22,24].

To date, there have been no studies that have analyzed the possible tendency to experience reinfection of IE due to anaerobes. These patients more often are men with poor dental hygiene and a prosthetic valve [25]. These cases frequently present large vegetation with extensive valvular destruction and congestive heart failure [26]. It is possible that the persistence of an unresolved polymicrobial and oligosymptomatic septic focus located in the digestive tract could be related to this type of reinfection. In any case, the reduced number of patients with this complication puts constraints on the importance of this finding.

Some variables related to reinfection observed in other studies, such as intravenous addiction or hemodialysis, may not have been detected because of the reduced number of patients who were exposed to these risk factors in our study [3,4].

4.4. Relationship between the Microbiology of the First Episode and That of the Second Episode in Patients with Reinfection

An innovative aspect of our study was the relationship between the microbiology of the first and second episodes in reinfected patients. The potential effect of antibiotics on the etiology of subsequent IE episodes has been observed previously [27]. Our results would suggest that previous treatment with cephalosporins (in the context of streptococcal endocarditis) may have favored the etiology of a second episode of IE to be enterococcal and that treatment for enterococci may have promoted the appearance of staphylococci in the next episode of IE.

\subsection{Limitations}

There are limitations to this study that need consideration. The main limitation is that no molecular biology studies were performed to corroborate that the cases considered as relapses were caused by the same strain. Another limitation is that patients with a new episode of IE caused by the initial bacterial species, where detection occurred six months after treatment, could not be reliably assigned to either group (relapses or reinfections). We would also like to draw attention to the low number of studied patients (especially in the relapse group) that may have prevented the identification of other associated clinical factors.

\section{Conclusions}

A better understanding of the clinical factors associated with recurrent episodes of IE can be helpful in informing patients and providers of the risks of reinfection and relapse. Although some of these factors are not modifiable, possible areas of research are identified, such as the role of surgery in cases where there is no established indication for surgery, 
but a high risk of relapse is deemed. Another line of future research is to study the best preventive strategy with regard to reinfection in patients with chronic liver disease or a history of prosthetic endocarditis.

Supplementary Materials: The following are available online at https:/ /www.mdpi.com/2077-038 3/10/4/748/s1, Table S1: Characteristics of the index episode of infectious endocarditis depending on whether the species causing the recurrence was the same or different from the initial episode. Table S2: Microbiology of the first (y-axis) and second episode (x-axis) of IE in cases of reinfection by a different microorganism.

Author Contributions: Conceptualization, J.C.-P., M.K., A.R.-M., J.M.P., A.F.-C. and P.M.; Data curation, M.K., A.R.-M., M.V., A.d.A., R.L., M.Á.G., T.E., M.C.F., G.O.-B., A.F.-C., A.P. and D.V.; Formal analysis, J.C.-P., M.K., A.R.-M., J.M.P., G.O.-B. and P.M.; Investigation, J.C.-P.; Supervision, M.K. and P.M.; Writing—original draft, J.C.-P., A.R.-M. and A.F.-C.; Writing—review \& editing, J.C.-P., M.K., A.R.-M., E.B., M.V., A.d.A., R.L., M.Á.G., T.E., M.C.F., J.M.P., G.O.-B., A.F.-C., A.P., D.V. and P.M. All authors have read and agreed to the published version of the manuscript.

Funding: This study has been conducted without receiving any funding.

Institutional Review Board Statement: The study was conducted according to the guidelines of the Declaration of Helsinki, and approved by Regional Clinical Research Ethics Committee of the Community of Madrid (CEIC-R), with approval code: 18/07.

Informed Consent Statement: Informed consent was obtained from all subjects involved in the study.

Data Availability Statement: The information contained in the database may be accessible after contacting the corresponding author and after its reasoned justification.

Acknowledgments: The authors of this manuscript are grateful for the collaboration of the researchers of the GAMES: Hospital Costa del Sol, (Marbella): Fernando Fernández Sánchez, Mariam Noureddine, Gabriel Rosas, Javier de la Torre Lima; Hospital Universitario de Cruces, (Bilbao): Roberto Blanco, María Victoria Boado, Marta Campaña Lázaro, Alejandro Crespo, Josune Goikoetxea, José Ramón Iruretagoyena, Josu Irurzun Zuazabal, Leire López-Soria, Miguel Montejo, Javier Nieto, David Rodrigo, Regino Rodríguez, Yolanda Vitoria, Roberto Voces; Hospital Universitario Virgen de la Victoria, (Málaga): Ma Victoria García López, Radka Ivanova Georgieva, Guillermo Ojeda, Isabel Rodríguez Bailón, Josefa Ruiz Morales; Hospital Universitario Donostia-Policlínica Gipuzkoa, (San Sebastián): Ana María Cuende, Tomás Echeverría, Ana Fuerte, Eduardo Gaminde, Miguel Ángel Goenaga, Pedro Idígoras, José Antonio Iribarren, Alberto Izaguirre Yarza, Xabier Kortajarena Urkola, Carlos Reviejo; Hospital General Universitario de Alicante, (Alicante): Rafael Carrasco, Vicente Climent, Patricio Llamas, Esperanza Merino, Joaquín Plazas, Sergio Reus; Complejo Hospitalario Universitario A Coruña, (A Coruña): Nemesio Álvarez, José María Bravo-Ferrer, Laura Castelo, José Cuenca, Pedro Llinares, Enrique Miguez Rey, María Rodríguez Mayo, Efrén Sánchez, Dolores Sousa Regueiro; Complejo Hospitalario Universitario de Huelva, (Huelva): Francisco Javier Martínez; Hospital Universitario de Canarias, (Canarias): $\mathrm{M}^{\mathrm{a}}$ del Mar Alonso, Beatriz Castro, Teresa Delgado Melian, Javier Fernández Sarabia, Dácil García Rosado, Julia González González, Juan Lacalzada, Lissete Lorenzo de la Peña, Alina Pérez Ramírez, Pablo Prada Arrondo, Fermín Rodríguez Moreno; Hospital Regional Universitario de Málaga, (Málaga): Antonio Plata Ciezar, José $\mathrm{M}^{a}$ Reguera Iglesias; Hospital Universitario Central Asturias, (Oviedo): Víctor Asensi Álvarez, Carlos Costas, Jesús de la Hera, Jonnathan Fernández Suárez, Lisardo Iglesias Fraile, Víctor León Arguero, José López Menéndez, Pilar Mencia Bajo, Carlos Morales, Alfonso Moreno Torrico, Carmen Palomo, Begoña Paya Martínez, Ángeles Rodríguez Esteban, Raquel Rodríguez García, Mauricio Telenti Asensio; Hospital Clínic-IDIBAPS, Universidad de Barcelona, (Barcelona): Manuel Almela, Juan Ambrosioni, Manuel Azqueta, Mercè Brunet, Marta Bodro, Ramón Cartañá, Carlos Falces, Guillermina Fita, David Fuster, Cristina García de la Mària, Delia García-Pares, Marta Hernández-Meneses, Jaume Llopis Pérez, Francesc Marco, José M. Miró, Asunción Moreno, David Nicolás, Salvador Ninot, Eduardo Quintana, Carlos Paré, Daniel Pereda, Juan M. Pericás, José L. Pomar, José Ramírez, Irene Rovira, Elena Sandoval, Marta Sitges, Dolors Soy, Adrián Téllez, José M. Tolosana, Bárbara Vidal, Jordi Vila; Hospital General Universitario Gregorio Marañón, (Madrid): Iván Adán, Javier Bermejo, Emilio Bouza, Daniel Celemín, Gregorio Cuerpo Caballero, Antonia Delgado Montero, Ana García Mansilla, Mª Eugenia García Leoni, Víctor González Ramallo, Martha Kestler Hernández, Amaia Mari Hualde, Mercedes Marín, Manuel Martínez-Sellés, Patricia Muñoz, Cristina Rincón, Hugo Rodríguez-Abella, 
Marta Rodríguez-Créixems, Blanca Pinilla, Ángel Pinto, Maricela Valerio, Pilar Vázquez, Eduardo Verde Moreno; Hospital Universitario La Paz, (Madrid): Isabel Antorrena, Belén Loeches, Alejandro Martín Quirós, Mar Moreno, Ulises Ramírez, Verónica Rial Bastón, María Romero, Araceli Saldaña; Hospital Universitario Marqués de Valdecilla, (Santander): Jesús Agüero Balbín, Carlos Armiñanzas Castillo, Ana Arnaiz, Francisco Arnaiz de las Revillas, Manuel Cobo Belaustegui, María Carmen Fariñas, Concepción Fariñas-Álvarez, Rubén Gómez Izquierdo, Iván García, Claudia González Rico, Manuel Gutiérrez-Cuadra, José Gutiérrez Díez, Marcos Pajarón, José Antonio Parra, Ramón Teira, Jesús Zarauza; Hospital Universitario Puerta de Hierro, (Madrid): Jorge Calderón Parra, Marta Cobo, Fernando Domínguez, Alberto Forteza, Pablo García Pavía, Jesús González, Ana Fernández Cruz, Elena Múñez, Antonio Ramos, Isabel Sánchez Romero; Hospital Universitario Ramón y Cajal, (Madrid): Tomasa Centella, José Manuel Hermida, José Luis Moya, Pilar Martín-Dávila, Enrique Navas, Enrique Oliva, Alejandro del Río, Jorge Rodríguez-Roda Stuart, Soledad Ruiz; Hospital Universitario Virgen de las Nieves, (Granada): Carmen Hidalgo Tenorio; Hospital Universitario Virgen Macarena, (Sevilla): Manuel Almendro Delia, Omar Araji, José Miguel Barquero, Román Calvo Jambrina, Marina de Cueto, Juan Gálvez Acebal, Irene Méndez, Isabel Morales, Luis Eduardo López-Cortés; Hospital Universitario Virgen del Rocío, (Sevilla): Arístides de Alarcón, Emilio García, Juan Luis Haro, José Antonio Lepe, Francisco López, Rafael Luque; Hospital San Pedro, (Logroño): Luis Javier Alonso, Pedro Azcárate, José Manuel Azcona Gutiérrez, José Ramón Blanco, Antonio Cabrera Villegas, Lara García-Álvarez, José Antonio Oteo, Mercedes Sanz; Hospital de la Santa Creu i Sant Pau, (Barcelona): Natividad de Benito, Mercé Gurguí, Cristina Pacho, Roser Pericas, Guillem Pons; Complejo Hospitalario Universitario de Santiago de Compostela, (A Coruña): M. Álvarez, A. L. Fernández, Amparo Martínez, A. Prieto, Benito Regueiro, E. Tijeira, Marino Vega; Hospital Santiago Apóstol, (Vitoria): Andrés Canut Blasco, José Cordo Mollar, Juan Carlos Gainzarain Arana, Oscar García Uriarte, Alejandro Martín López, Zuriñe Ortiz de Zárate, José Antonio Urturi Matos; Hospital SAS Línea de la Concepción, (Cádiz): García-Domínguez Gloria, Sánchez-Porto Antonio; Hospital Clínico Universitario Virgen de la Arrixaca (Murcia): José Ma Arribas Leal, Elisa García Vázquez, Alicia Hernández Torres, Ana Blázquez, Gonzalo de la Morena Valenzuela; Hospital de Txagorritxu, (Vitoria): Ángel Alonso, Javier Aramburu, Felicitas Elena Calvo, Anai Moreno Rodríguez, Paola Tarabini-Castellani; Hospital Virgen de la Salud, (Toledo): Eva Heredero Gálvez, Carolina Maicas Bellido, José Largo Pau, Ma Antonia Sepúlveda, Pilar Toledano Sierra, Sadaf Zafar Iqbal-Mirza; Hospital Rafael Méndez, (Lorca-Murcia): Eva Cascales Alcolea, Ivan Keituqwa Yañez, Julián Navarro Martínez, Ana Peláez Ballesta; Hospital Universitario San Cecilio (Granada): Eduardo Moreno Escobar, Alejandro Peña Monje, Valme Sánchez Cabrera, David Vinuesa García; Hospital Son Llátzer (Palma de Mallorca): María Arrizabalaga Asenjo, Carmen Cifuentes Luna, Juana Núñez Morcillo, $\mathrm{M}^{\text {a }}$ Cruz Pérez Seco, Aroa Villoslada Gelabert; Hospital Universitario Miguel Servet (Zaragoza): Carmen Aured Guallar, Nuria Fernández Abad, Pilar García Mangas, Marta Matamala Adell, Ma Pilar Palacián Ruiz, Juan Carlos Porres; Hospital General Universitario Santa Lucía (Cartagena): Begoña Alcaraz Vidal, Nazaret Cobos Trigueros, María Jesús Del Amor Espín, José Antonio Giner Caro, Roberto Jiménez Sánchez, Amaya Jimeno Almazán, Alejandro Ortín Freire, Monserrat Viqueira González; Hospital Universitario Son Espases (Palma de Mallorca): Pere Pericás Ramis, Mª Ángels Ribas Blanco, Enrique Ruiz de Gopegui Bordes, Laura Vidal Bonet; Complejo Hospitalario Universitario de Albacete (Albacete): $\mathrm{M}^{\mathrm{a}}$ Carmen Bellón Munera, Elena Escribano Garaizabal, Antonia Tercero Martínez, Juan Carlos Segura Luque; Hospital Universitario Terrassa: Cristina Badía, Lucía Boix Palop, Mariona Xercavins, Sónia Ibars. Hospital Universitario Negrín (Gran Canaria): Eloy Gómez Nebreda, Ibalia Horcajada Herrera, Irene Menduiña Gallego. Complejo Hospitalario Universitario Insular Materno Infantil (Las Palmas de Gran Canaria): Héctor Marrero Santiago, Isabel de Miguel Martínez, Elena Pisos Álamo. Hospital Universitario 12 de Octubre (Madrid): Carmen Díaz Pedroche, Fernando Chaves, Santiago de Cossío, Francisco López Medrano, $\mathrm{M}^{\mathrm{a}}$ Jesús López, Javier Solera, Jorge Solís. Hospital Universitari Bellvitge (Barcelona): Carmen Ardanuy, Guillermo Cuervo Requena, Sara Grillo, Alejandro Ruiz Majoral.

Conflicts of Interest: The authors declare no conflict of interest.

\section{Abbreviations}

IE: infective endocarditis, TTE: transthoracic echocardiography, TEE: transesophageal echocardiography, IQR: interquartile ranges, EVL: endoscopic variceal ligation. 


\section{References}

1. David, T.E.; Gavra, G.; Feindel, C.M.; Regesta, T.; Armstrong, S.; Maganti, M.D. Surgical treatment of active infective endocarditis: A continued challenge. J. Thorac. Cardiovasc. Surg. 2007, 133, 144-149. [CrossRef] [PubMed]

2. Anguita Sánchez, M.; Torres Calvo, F.; Castillo Domínguez, J.C.; Delgado Ortega, M.; Mesa Rubio, D.; Ruiz Ortiz, M.; Romo Peña, E.; Arizón del Prado, J.M.; Suarez de Lezo, J. Short- and long-term prognosis of infective endocarditis in non-injection drug users: Improved results over 15 years (1987-2001). Rev. Esp. Cardiol. 2005, 58, 1188-1196. [CrossRef]

3. Alagna, L.; Park, L.P.; Nicholson, B.P.; Keiger, A.J.; Strahilevitz, J.; Morris, A.; Wray, D.; Gordon, D.; Delahaye, F.; Edathodu, J.; et al. Repeat endocarditis: Analysis of risk factors based on the International Collaboration on Endocarditis-Prospective Cohort Study. Clin. Microbiol. Infect. 2014, 20, 566-575. [CrossRef]

4. Freitas-Ferraz, A.B.; Tirado-Conte, G.; Vilacosta, I.; Olmos, C.; Sáez, C.; López, J.; Sarriá, C.; Pérez-García, C.N.; García-Arribas, D.; Ciudad, M.; et al. Contemporary epidemiology and outcomes in recurrent infective endocarditis. Heart 2019, 106, 596-602. [CrossRef]

5. Mansur, A.J.; Bo, C.M.D.; Fukushima, J.T.; Issa, V.S.; Grinberg, M.; Pomerantzeff, P.M. Relapses, recurrences, valve replacements, and mortality during the long-term follow-up after infective endocarditis. Am. Heart J. 2001, 141, 78-86. [CrossRef] [PubMed]

6. Lossos, I.S.; Oren, R. Recurrent infective endocarditis. Postgrad. Med. J. 1993, 69, 816-818. [CrossRef] [PubMed]

7. Rudasill, S.E.; Sanaiha, Y.; Mardock, A.L.; Khoury, H.; Xing, H.; Antonios, J.W.; McKinnell, J.A.; Benharash, P. Clinical Outcomes of Infective Endocarditis in Injection Drug Users. J. Am. Coll. Cardiol. 2019, 73, 559-570. [CrossRef]

8. Chu, V.H.; Sexton, D.J.; Cabell, C.H.; Barth, R.L.; Pappas, P.A.; Singh, R.K.; Fowler, V.G.; Ralph, C.G.; Aksoy, O.; Woods, C.W. Repeat Infective Endocarditis: Differentiating Relapse from Reinfection. Clin. Infect. Dis. 2005, 41, 406-409. [CrossRef] [PubMed]

9. Renzulli, A.; Carozza, A.; Romano, G.; De Feo, M.; Della Corte, A.; Gregorio, R.; Cotrufo, M. Recurrent infective endocarditis: A multivariate analysis of 21 years of experience. Ann. Thorac. Surg. 2001, 72, 39-43. [CrossRef]

10. Fernández-Hidalgo, N.; Almirante, B.; Tornos, P.; Pigrau, C.; Sambola, A.; Igual, A.; Pahissa, A. Contemporary Epidemiology and Prognosis of Health Care-Associated Infective Endocarditis. Clin. Infect. Dis. 2008, 47, 1287-1297. [CrossRef]

11. Martínez-Sellés, M.; Muñoz, P.; Arnáiz, A.; Moreno, M.; Gálvez, J.; Rodríguez-Roda, J.; De Alarcón, A.; Cabrera, E.G.; Fariñas, M.C.; Miró, J.M.; et al. Valve surgery in active infective endocarditis: A simple score to predict in-hospital prognosis. Int. J. Cardiol. 2014, 175, 133-137. [CrossRef]

12. Li, J.S.; Sexton, D.J.; Mick, N.; Nettles, R.; Fowler, J.V.G.; Ryan, T.; Bashore, T.; Corey, G.R. Proposed Modifications to the Duke Criteria for the Diagnosis of Infective Endocarditis. Clin. Infect. Dis. 2000, 30, 633-638. [CrossRef] [PubMed]

13. Habib, G.; Lancellotti, P.; Antunes, M.J.; Bongiorni, M.G.; Casalta, J.-P.; Del Zotti, F.; Dulgheru, R.; El Khoury, G.; Erba, P.A.; Iung, B.; et al. 2015 ESC Guidelines for the management of infective endocarditis. The Task Force for the Management of Infective Endocarditis of the European Society of Cardiology (ESC). Eur. Heart J. 2016, 17, 3075-3128.

14. Charlson, M.E.; Pompei, P.; Ales, K.L.; MacKenzie, C. A new method of classifying prognostic comorbidity in longitudinal studies: Development and validation. J. Chronic Dis. 1987, 40, 373-383. [CrossRef]

15. Cockcroft, D.W.; Gault, M.H. Prediction of creatinine clearance from serum creatinine. Nephron 1976, 16, 31-41. [CrossRef] [PubMed]

16. Endorsed by the European Society of Clinical Microbiology and Infectious Diseases (ESCMID) and by the International Society of Chemotherapy (ISC) for Infection and Cancer; Habib, G.; Hoen, B.; Tornos, P.; Thuny, F.; Prendergast, B.; Vilacosta, I.; Moreillon, P.; Antunes, M.D.J.; Thilen, U.; et al. Guidelines on the prevention, diagnosis, and treatment of infective endocarditis (new version 2009): The Task Force on the Prevention, Diagnosis, and Treatment of Infective Endocarditis of the European Society of Cardiology (ESC). Eur. Heart J. 2009, 30, 2369-2413.

17. Fernandez-Hidalgo, N.; Almirante, B.; Tornos, P.; González-Alujas, M.T.; Planes, A.M.; Galiñanes, M.; Pahissa, A. Immediate and long-term outcome of left-sided infective endocarditis. A 12-year prospective study from a contemporary cohort in a referral hospital. Clin. Microbiol. Infect. 2012, 18, E522-E530. [CrossRef]

18. Tornos, M.-P.; Permanyer-Miralda, G.; Olona, M.; Gil, M.; Galve, E.; Almirante, B.; Soler-Soler, J. Long-Term Complications of Native Valve Infective Endocarditis in Non-Addicts. Ann. Intern. Med. 1992, 117, 567-572. [CrossRef] [PubMed]

19. Pericàs, J.M.; Cervera, C.; Moreno, A.; Garcia-de-la-Mària, C.; Almela, M.; Falces, C.; Quintana, E.; Vidal, B.; Llopis, J.; Fuster, D.; et al. Outcome of Enterococcus faecalis infective endocarditis according to the length of antibiotic therapy: Preliminary data from a cohort of 78 patients. PLoS ONE 2018, 13, e0192387.

20. Fernández Guerrero, M.L.; Goyenechea, A.; Verdejo, C.; Roblas, R.F.; de Górgolas, M. Enterococcal endocarditis on native and prosthetic valves: A review of clinical and prognostic factors with emphasis on hospital-acquired infections as a major determinant of outcome. Medicine (Baltimore) 2007, 86, 363-377. [CrossRef] [PubMed]

21. Martínez, A.R.; Pericàs, J.M.; Fernández-Cruz, A.; Muñoz, P.; Valerio, M.; Kestler, M.; Montejo, M.; Fariñas, M.C.; Sousa, D.; Domínguez, F.; et al. Four weeks versus six weeks of ampicillin plus ceftriaxone in Enterococcus faecalis native valve endocarditis: A prospective cohort study. PLoS ONE 2020, 15, e0237011.

22. Lin, O.S.; Wu, S.S.; Chen, Y.Y.; Soon, M.S. Bacterial peritonitis after elective endoscopic variceal ligation: A prospective study. Am. J. Gastroenterol. 2000, 95, 214-217. [CrossRef] [PubMed]

23. Hung, T.H.; Hsieh, Y.H.; Tseng, K.C.; Tsai, C.C.; Tsai, C.C. The risk for bacterial endocarditis in cirrhotic patients: A populationbased 3-year follow-up study. Int. J. Infect. Dis. 2013, 17, e391-e393. [CrossRef] [PubMed] 
24. Allaire, M.; Ollivier-Hourmand, I.; Garioud, A.; Heng, R.; Dao, T.; Cadranel, J.D. Infectious endocarditis in the case of cirrhosis: Where do we stand? Eur. J. Gastroenterol. Hepatol. 2018, 30, 1406-1410. [CrossRef] [PubMed]

25. Kestler, M.; Muñoz, P.; Marín, M.; Goenaga, M.; Idíforas Viedma, P.; De Alarcón, A.; Lepe, J.; Sousa Regueiro, D.; Bravo-Ferrer, J.; Pajarón, M.; et al. Endocarditis caused by anaerobic bacteria. Anaerobe 2017, 47, 33-38. [CrossRef]

26. Brook, I. Infective endocarditis caused by anaerobic bacteria. Arch. Cardiovasc. Dis. 2008, 101, 665-676. [CrossRef]

27. Ramos-Martínez, A.; Cobo, M.; Restrepo, A.; Mucientes, J.; Orden-Martínez, B.; Rodríguez-Alfonso, B. Colonoscopy and Endocarditis: A Compromised Relationship. Rev. Esp. Cardiol. (Engl. Ed.) 2018, 71, 862-864. [CrossRef] 